\title{
Diurnal Characteristics of Angstrom Turbidity Parameters Over Manila, Philippines
}

\author{
Rhonalyn L. Vergara ${ }^{1}$, Ernest P. Macalalad ${ }^{2}$ Gerry Bagtasa $^{3}$, Edgar A. Vallar ${ }^{4}$, \\ and Maria Cecilia D. Galvez \\ ${ }^{I}$ (Philippine Atmospheric Geophysical and Astronomical Services Administration - Department of Science and \\ Technology, Science Garden Complex, Agham Road, Diliman, Quezon City, Philippines) \\ 2 (Institute of Space Science, National Central University, Jhongli City, Taoyuan County, Taiwan (R.O.C.)) \\ ${ }^{3}$ (Institute of Environmental Science \& Meteorology, University of the Philippines, \\ Diliman, Quezon City, Philippines) \\ ${ }^{4}$ (Physics Department, De La Salle University, 2401 Taft Avenue, Malate, Manila 1004, Philippines)
}

\begin{abstract}
The diurnal variation of the aerosol optical depth (AOD) at 500nm wavelength and the Angstrom turbidity coefficients ( $\alpha$ and $\beta$ ) were derived from direct beam measurements. Results of the measurements showed that the $A O D, \alpha$, and $\beta$ variations at different time intervals were mainly influenced by human activities and industrial operations as the day progressed. Hourly variability of $A O D$ (in terms of percent departure from the daily mean) showed that it increases from morning and then reaches its maximum diversion from the mean (25\%) at noontime (around $11 \mathrm{AM}$ local time) and then slowly decreases in the afternoon. The wavelength exponent showed an almost similar pattern of diurnal variability as AOD. Its variation ranges at about $6 \%$ above and below the average value of $\alpha$. However $\beta$ has a different pattern as compared to AOD and $\alpha$. It consistently departs above the mean at around $20 \%$ in the morning and close to $30 \%$ below the mean in the afternoon. Daily values of AOD range from 0.545 to 2.174 with values frequently in the range of 0.5 to 1.5 . Daily a was frequently around 1.75 but its values ranged from 0.502 to 3.236. This denoted that fine particles were dominating over coarse particles.
\end{abstract}

Keywords : Angstrom turbidity coefficients, aerosol, optical depth, wavelength exponent, sunphotometer

\section{INTRODUCTION}

Aerosols are fine solid particles and liquid droplets which are suspended in the atmosphere. They can be naturally occurring (e.g., those that stemmed from volcanic dust, dust storms, fires, vegetation and sea sprays) or anthropogenic (e.g., those generated from the burning of fossil fuels). These aerosols perform a significant role not only in the atmosphere and its processes but also in people's health and welfare around the world. Apart from their ability to scatter and absorb solar and terrestrial radiation, plus modifying the climate as they act as cloud condensation nuclei $(\mathrm{CCN})$ [1], these particles are highly associated with air quality and pollution. Thus, the need for understanding their physical, chemical and optical properties is essential in order to recognize their complex nature and how they affect climate and society [2]. Aerosols which are mostly found in the Earth's troposphere are the ones associated with air pollution. These are the ones responsible for poor air quality, reduction of visibility and even health hazards [3]. Information on air quality in terms of the amount of aerosol as well as the role of meteorology in air pollution has drawn much attention in the recent years especially in the cities wherein the concentration of air pollution (due to human activities, transportation, construction and biomass burning), and its consequences in relation to health, is significantly growing like in Metro Manila, Philippines [4]. Manila is situated adjacent to Manila Bay and it is where there are several industries, commercial sites and urban settlements located. Manila is subjected to both maritime and continental/urban aerosols that pose a serious threat to its resident's health due to their high concentration and by continuous exposure [5,6]. Measurement of the atmospheric turbidity is one way of determining atmospheric aerosol content. The turbidity index (such as AOD) and the Ångstrom turbidity parameters, which are the Ångstrom turbidity coefficient ( $\beta$ ) and Ångstrom wavelength exponent $(\alpha)$, are some of the parameters that can be used as a measure of air pollution through spectral or broadband radiation. The higher the AOD value, the more aerosols are within a column, and the lower the visibility within that column [7]. In this paper, we present and analyze the diurnal characteristics of $\alpha$ and $\beta$ obtained from a one year period (August 2009 July 2010) of solar radiation measurements using an SP02 Middleton Sunphotometer with center wavelengths at $368 \mathrm{~nm}, 500 \mathrm{~nm}, 675 \mathrm{~nm}$, and $862 \mathrm{~nm}$. 


\section{THE SAMPLING SITE}

Solar radiation measurements were performed by the Environment And RemoTe sensing researcH (EARTH) group of the Physics Department of De La Salle University (DLSU). As seen in Figure 1, De La Salle University is located in the City of Manila, which is on the eastern shore of Manila Bay. Manila is bordered by the cities of Malabon and Caloocan to the north; Quezon City to the northeast; San Juan and Mandaluyong to the east; Makati to the southeast, and Pasay to the south. The observation site is approximately $900 \mathrm{~m}$ from Manila Bay and $20 \mathrm{~m}$ above sea level. It is also flanked by Manila's busiest avenues like Roxas Boulevard, President Quirino Avenue, Taft Avenue, Pablo Ocampo Street and Gil Puyat Avenue. According to the Department of Science and Technology-Philippine Atmospheric, Geophysical, and Astronomical Services Administration (DOST-PAGASA), Manila features a tropical and maritime climate characterized by relatively high temperature, high humidity and abundant rainfall; similar in many respects to the climate of the countries of Central America. Manila has two pronounced seasons, dry from November to April, and wet during the rest of the year. June to September is the period with maximum rainfall.

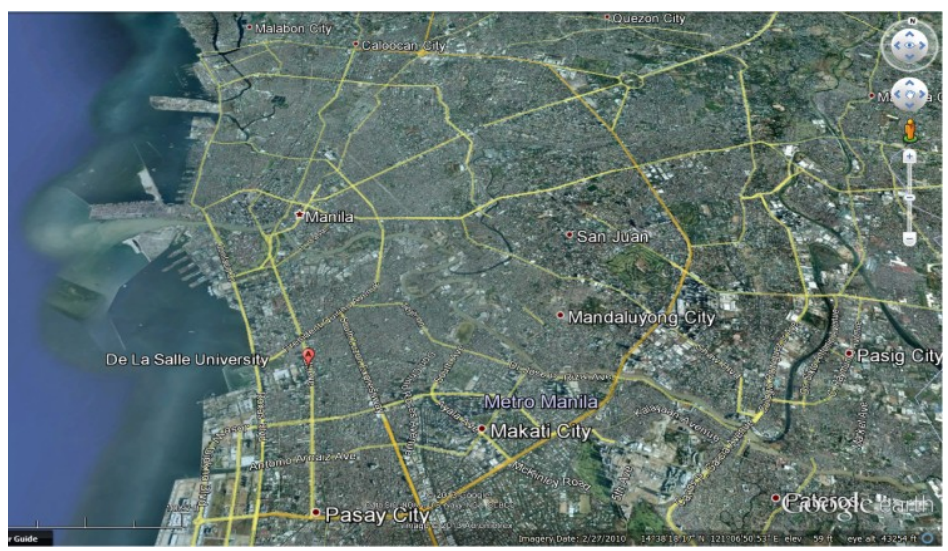

Figure 1. Vicinity map of the sampling site. (Source: $14^{\circ} 38^{\prime} 18.17^{\prime \prime} \mathrm{N}, 121^{\circ} 06$ '50.53"E. Google Earth. February 27, 2010. February 1, 2013.)

\section{Methodology}

The Ångstrom turbidity parameters give valuable information on aerosol properties and important trace gases. These parameters are dimensionless measures of the opacity of a vertical column of the atmosphere and a numerical quantification of the column extinction of transmitted radiation by atmospheric aerosols from a fixed band in the solar electromagnetic spectrum [6, 8-10]. The relationship among these quantities is given by the Angstrom turbidity law:

$$
\tau_{a}(\lambda)=\beta \lambda^{-\alpha}
$$

where $\tau(\lambda)$ is the atmospheric optical depth (AOD) which is a dimensionless quantity that gives a measure of how much aerosols attenuate solar radiation, $\beta$ is the Angstrom turbidity coefficient and $\alpha$ is the wavelength exponent. The Ångstrom turbidity coefficient $(\beta)$ represents the atmospheric aerosol content in the vertical direction. It is the extinction coefficient corresponding to $1-\mu \mathrm{m}$ wavelength. Typically, the values of $\beta$ range from 0.0 to 0.5 wherein values like $0.0,0.1,0.2$ and 0.4 correspond to a clean, clear, turbid and a very turbid atmosphere, respectively [11-13]. This means that, the larger the value of $\beta$, the more turbid the atmosphere is. The wavelength exponent $(\alpha)$ denotes the average aerosol size distribution of the scattering particles. The typical values of $\alpha$ range from 0.5 to 2.5 but for most atmospheres, its value is around $1.3[14,15]$. $\alpha$ higher than 1.3 indicates the presence of urban-sized aerosols while value less than 1.3 indicates the existence of maritime aerosols. This law is accurate for a Junge aerosol distribution [16].

\section{RESULTS AND DISCUSSION}

Atmospheric aerosol optical properties such as the aerosol optical depth (AOD), wavelength exponent $(\alpha)$, and Ångstrom turbidity coefficient $(\beta)$ were obtained for 144 days during a 1-year period (August 2009July 2010). From this, thirty six (36) were considered as clear-sky days. $78 \%$ of these days were found in the months of February to May. Limited data were retrieved from September to January due to the removal of cloud contaminated data and also due to the unavailability of clear sky conditions during those months. The least number of observed data was recorded in January as some repair works were done on the instrument during this period. Figure 2 presents the number of non-cloudy days recorded per month. 


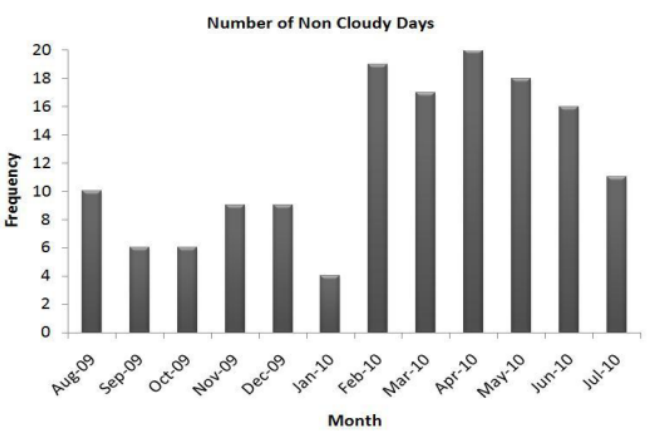

Figure 2. Frequency distribution of data obtained per month from August 2009 to July 2010.

\section{1) Frequency Distribution}

The frequency distributions of the observed parameters have revealed the presence of individual modes of high and low AOD values, indicating the influence of different sources. The frequency plot per time interval of AOD, presented in Figure 3 A-D, shows that the AOD values during early to mid-morning $(0700-0930 \mathrm{H})$, are from 0.75 to 3.00 with most measurements having an AOD value of around 0.8 (mode $=0.83$ ). From mid to late morning (0930-1200H), where human activities become more active and the sun shines more intensely, the peak of the distribution curve shifts to 1.00 (mode $=0.97)$ and the distribution extends to higher AOD values $(\sim 4.00)$ which indicates higher concentration of aerosols. The maximum observed AOD is at 1.00 (mode $=0.97$ ) in the early afternoon bracket $(1200-1430 \mathrm{H})$ but with greater frequency which entails the spread of aerosols in the sky. As the day concludes, during the late afternoon $(1430-1700 \mathrm{H})$, the prevailing AOD goes back to lower values with highest frequency occurring at 0.75 (mode $=0.79$ ). It implies that AOD variability is based on human activities during the day which contributes to the concentration of aerosols. Also, it follows how the sun heats the surface (affecting the mixing height). This suggests that this pattern is mainly driven by the effect of RH and local circulation systems persistent under certain meteorological conditions. Metro Manila is close to a body of water wherein it is in phase with the winds moving westward. The wind carries maritime aerosols to the atmosphere. Meanwhile, Figure 4 A-D gives an idea of the diurnal trend of $\beta$ at different time intervals. It demonstrates the same trend as AOD from early morning to late afternoon wherein most values occur at 0.10 (mode $=0.11$ ) and the range extends up to more or less 2.75. It can be associated with the presence of emission sources during the day (such as transportation and industrial activities); from the time they start operations in the morning and their increase in magnitude as the day progresses.
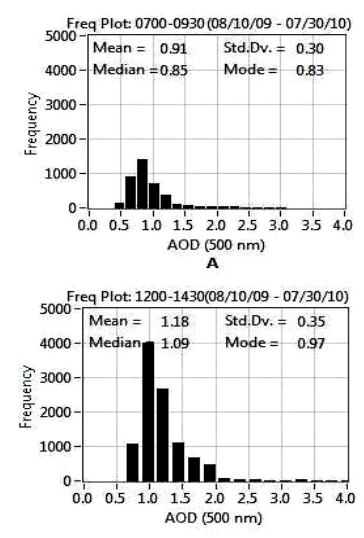

c

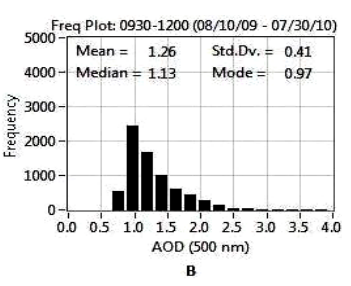

B

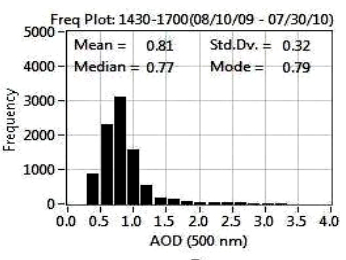

D

Figure 3. Frequency distribution of AOD at different time intervals: (A) 0700-0930H, (B) 0930-1200H, (C) 1200-1430H and (D) $1430-1700 \mathrm{H}$ local time.

In the case of $\alpha$, Figure 5 A-D shows the variation of frequency distribution at different time sets of the day. The frequency of $\alpha$ recorded during the early morning is minimal. Its maximum frequency occurs at around 1.75 (mode $=1.68)$. Its distribution around the highest concentration is narrow compared with the other time intervals where the values vary more. Higher rates of recurrence are noted during the late morning and the value extends up to 3.5 having a majority around 2.00 (mode $=1.96$ ). This means aerosols which are smaller in size (continental and urban aerosol) are gradually increasing in concentration. In the afternoon, $\alpha$ are leaning toward higher values while maintaining peak values at 2.00 and at 2.5 . Still, majority of $\alpha$ with values at 2.00 prevails as the day ends with a wider spread of distribution ranging from -1.9 to 3.5. Negative values of $\alpha$ indicate the presence of very large particles that have drifted in the line of sight of the sunphotometer. This usually happens during the afternoon when the sunphotometer faces the maritime region where the bigger particles originate. 

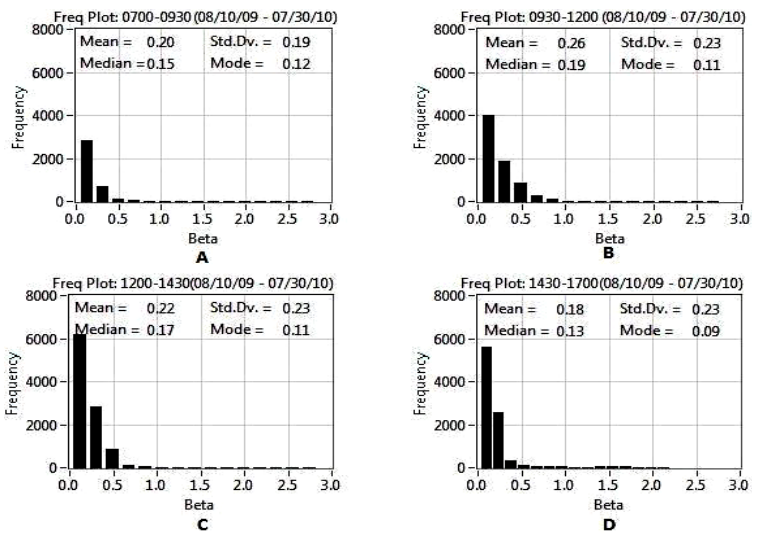

Figure 4. Frequency distribution of $\beta$ at different time intervals: (A) 0700-0930H, (B) 0930-1200H, (C) 1200$1430 \mathrm{H}$ and (D) $1430-1700 \mathrm{H}$ local time.
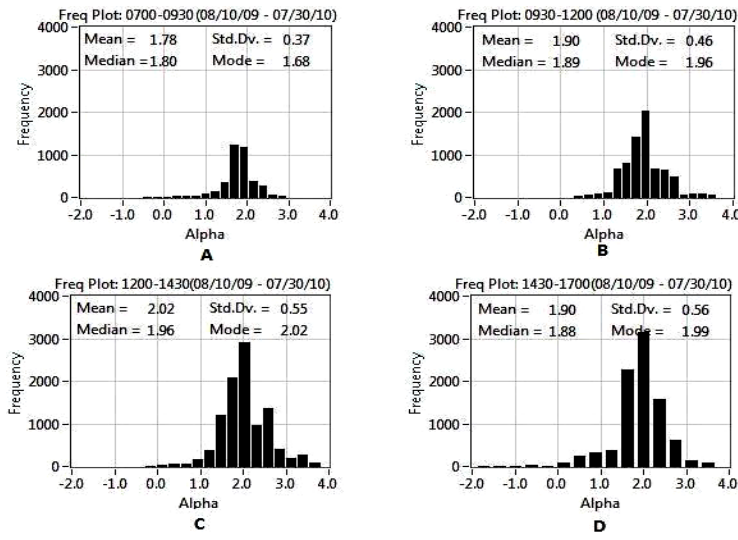

Figure 5. Frequency distribution of $\alpha$ at different time intervals (A) 0700-0930H, (B) 0930-1200H, (C) 1200$1430 \mathrm{H}$ and (D) $1430-1700 \mathrm{H}$ local time.

These negative values are eliminated in the calculation of the mean for the analysis. The frequency distribution implies that, as the day ends, diverse kinds of aerosols (continental and maritime) at different sizes are already in the sky. Researchers in Northern Greece [17] observed a similar pattern in their study about the climatological aspects of aerosol properties in Greece where the diurnal variability of $\alpha$ indicates changes in the aerosol types associated with the wind direction.

\section{2) Hourly (Daytime) Variation}

The hourly variation of the aerosol optical properties was computed on a yearly basis as percent departure from the daily mean and is shown in Figure 6. Each hourly average consists of a total of 1440 observations. There is a clear daytime hourly cycle of AOD during the one year observation period. The AOD is increasing as the morning progresses, reaches its peak around noon, and then decreases in the afternoon. Figure $6 \mathrm{~A}$ shows a percentage of departure of about $-4 \%$ at $9 \mathrm{AM}$ and $-32 \%$ at $4 \mathrm{PM}$ with its peak at an hour before noontime $(25 \%$ at $11 \mathrm{AM})$. This periodicity of AOD shows that its variability lie within a $\pm 30 \%$ range. This signifies that there is an increase in the AOD as the day progresses, reaching its peak at noontime, and decreases in the afternoon as explained previously. The pattern in AOD diurnal variations shown in this study is in good agreement with Smirnov et al., [18], where the diurnal trend for Ronnest Island (20 km from the coast of
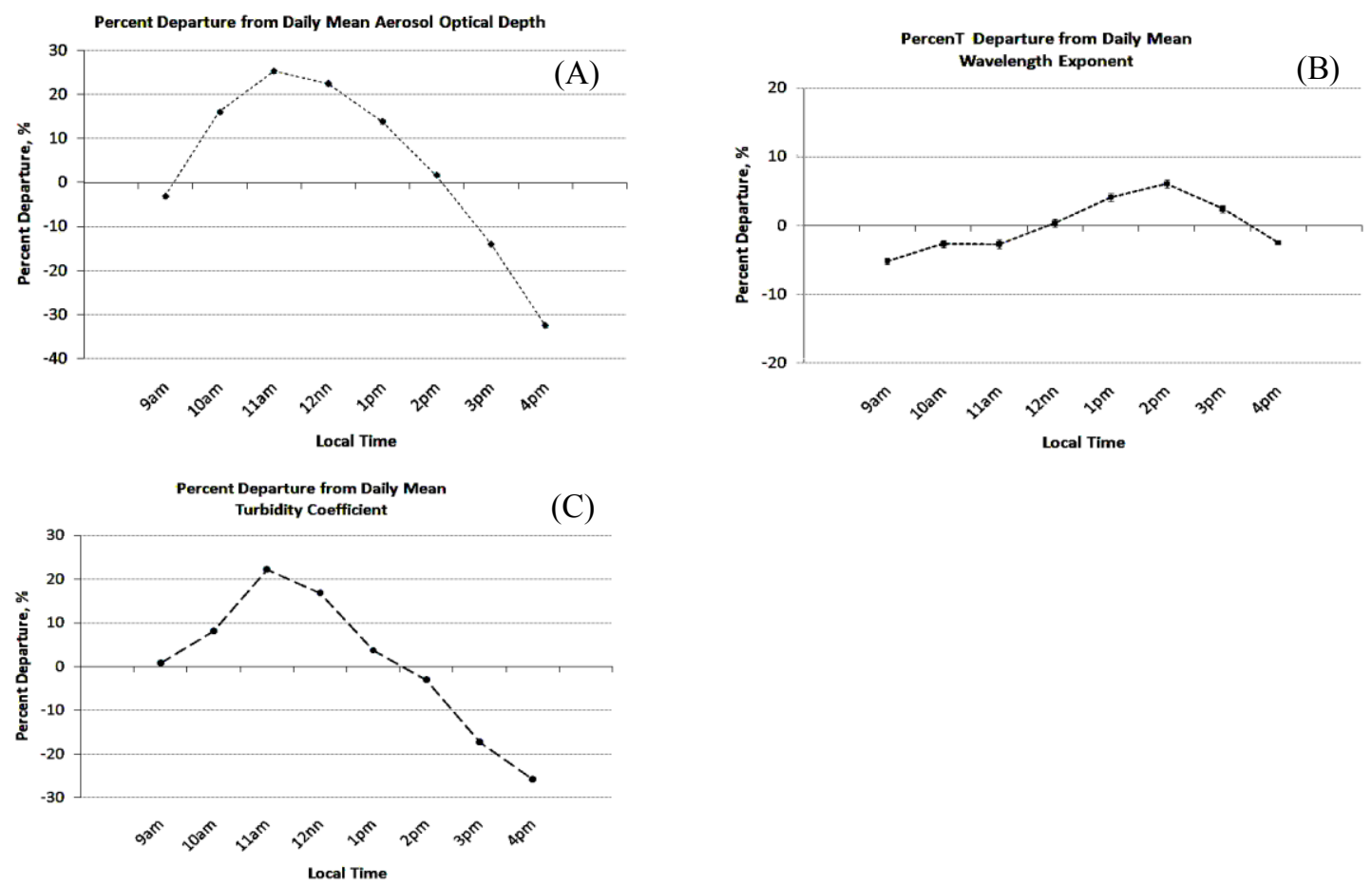

\section{C)}

Figure 6. Percent Departure from the Daily Mean A.) Aerosol Optical Depth; B.) Wavelength Exponent; C.) Ångstrom Turbidity Coefficient. 
Western Australia) shows a pronounced increase during the midday up to its maximum, and a slow decrease in the afternoon. It is believed that local pollutants along with atmospheric convection likely play a major role in the diurnal behavior of the aerosol optical depth. The wavelength exponent variation lies within $6 \%$ above and below the daily mean. Figure 6B shows that $\alpha$ increases gradually every hour until 2PM and goes down in the afternoon. Most of the morning hourly observations show that $\alpha$ is below the daily mean. This suggests a changing in the aerosol types or the introduction of different types and concentration as the day moves forward. Due to inversion, more fine particles lead to an increase in $\alpha$ [19]. A pattern almost similar to the AOD was observed in the case of the Angstrom turbidity coefficient (Figure 6C). During the morning, the degree of departure is increasing up to about $20 \%$. At $11 \mathrm{AM}$ it decreases abruptly equaling the mean (close to $2 \mathrm{PM}$ ) and moves below the mean in the afternoon in a seemingly constant rate of departure $(10 \%)$. The average increase above the mean in the morning is almost double the average decrease below the mean in the afternoon. This variability is linked to local sources and particle concentration.

\section{CONCLUSION}

The diurnal variation of $\mathrm{AOD}$ at $500 \mathrm{~nm}$ wavelength, $\alpha$, and $\beta$ were derived from direct beam measurements. The variation of the AOD at different time intervals; $(0700-0930 \mathrm{H}),(0930-1200 \mathrm{H}),(1200-$ $1430 \mathrm{H})$ and $(1430-1700 \mathrm{H})$ with maximum frequency occurring at $0.83,0.97,0.97$ and 0.79 , respectively, showed that the AOD was mainly influenced by human activities and industrial operations as the day progressed. Its trend was also attributed to the sun's heating of the surface and sea breeze circulation affecting the mixing height movement which carries much of the aerosols in the atmosphere from morning to late afternoon. The Ångstrom turbidity coefficient followed the same trend as the AOD during the day wherein the values extended up to a maximum of 2.5 with an average value about 0.11 . This was attributed also to human activities (such as the use of individual transport) which starts in the morning and increase in number as the day steps forward. On the other hand, the diurnal trend of $\alpha$ illustrates that it peaks at 1.75 in the early morning $(0700-0930 \mathrm{H})$ with a very narrow range. Particles smaller in size then began to enter in the late morning which extends the values of $\alpha$ up to 3.5 with frequency peaks around 2.0. In the afternoon, $\alpha$ leaned toward higher values but was concentrated at two points (2.0 and 2.5). Finally, in the late afternoon, the values spread up to 3.5 and a maximum close to 2.0 signifying the presence of more diverse kinds of particles. This was due to the wind flow pattern (from sea to land) which introduced the presence of a different aerosol type. The hourly variability of the AOD (in terms of percent departure from the daily mean) showed that it increases in the morning, reaches its maximum departure (about 25\%) around noontime (11 AM), and then slowly decreases in the afternoon. The wavelength exponent showed an almost similar pattern of diurnal variability as the AOD. It departs from the mean and reaches its maximum at 2 PM. Its variation ranges at about $6 \%$ above and below the average value of $\alpha$. However, $\beta$ has a different pattern compared with the AOD and $\alpha$. It is consistently above the mean (with a maximum of around $20 \%$ ) in the morning and reaches close to $30 \%$ below the mean in the afternoon. The daily values of AOD range from 0.545 to 2.174 with values frequently within the range of 0.5 to 1.5 . Daily $\alpha$ varied from 0.502 to 3.236 and was recurrent at 1.75 . This denoted that fine particles were dominating over coarse particles.

\section{REFERENCES}

[1] C. W. Chiang, W. N. Chen, W. A. Liang, S. K. Das, J.B. Nee, "Optical Properties of Tropospheric Aerosols Based on Measurements of Lidar, Sunphotometer and Visibility at Chung-Li”, Atmospheric Environment, Vol. 41, 2007, pp. $4128-4137$.

[2] J.L. Handa, S.M. Kreidenweis, J. Slusser, G. Scott, Hand, "Comparisons of Aerosol Optical Properties Derived from Sunphotometry to Estimates Inferred from Surface Measurements in Big Bend National Park, Texas”, Atmospheric Environment, Vol. 38, 2004, pp. 6813-8621.

[3] Y. Zhang, Z. Wang, L. Chen, and X. Gu. (2008, July 6-11). "Retrieval of Aerosol from CBERS02B using Contrast Reduction Method in Beijing". Paper presented at the 2008 IEEE International Geoscience \& Remote Sensing Symposium (IGARSS 2008). doi: 10.1109/IGARSS.2008.4779509

[4] N. Kumar, A. Chu, and A. Foster, "An Empirical Relationship Between PM 2.5 and Aerosol Optical Depth in Delhi Metropolitan", Atmospheric Environment, Vol. 41, 2007, pp. 4492-4503.

[5] [EURO] World Health Organization. Europe. 2005. Particulate Matter Air Pollution: How it Harms Health. Fact Sheet EURO04/05:1-3

[6] K.A. Esguerra, "Comparison of Aerosol Optical Properties using Lidar and Sunphotometer over De La Salle University - Manila". [Undergraduate Thesis] De La Salle University- Dasmarinas, 2010.

[7] G. Carmichael, et. al., "Asian Aerosols: Current and Year 2030 Distributions and Implications to Human Health and Regional Climate Change”, Environ. Sci. Technol., Vol. 43, 2009, pp. 5811-5817.

[8] F. M. Mims, III, “An international haze-monitoring network for students," Bulletin of the American Meteorological Society, 1999, Vol. 80, pp. 1421-1431.

[9] E. M. Rollin, "An introduction to the use of Sunphotometry for the atmospheric correction of airborne sensor data," Activities of the NERC EPFS in support of the NERC ARSF. ARSF Annual Meeting, Keyworth, Nottingham, UK., 2000.

[10] E. P. Macalalad, "Retrieval of Multi-spectral Aerosol Optical Depth (AOD) and Development of a Sun Tracking Device for the SP101 and SP02 Sunphotometers," [Undergraduate Thesis] De La Salle University-Manila, 2004.

[11] E.P. Macalalad, "Determination of Atmospheric Turbidity Parameters and Aerosol Size Distribution Using a Feedback-Controlled Sun Tracking Sunphotometer over Manila”, [Master's Thesis] De La Salle University- Manila, 2006. 
[12] D. Brooks, "First Results from the GLOBE sun photometer", in 5th GLOBE Annual Meeting, Drexel University, PA., 16-20 July 2000 .

[13] W. M. Keogh and A. W. Blakers, "Accurate Measurement, Using Natural Sunlight, of Silicon Solar Cells," Progress in Photovoltaics: Research and Applications, Vol. 12, 2004, pp. 1-19.

[14] V. E. Cachorro, A. M. de Frutos and J. Casanova, "Determination of the Ångström turbidity parameters", Applied Optics, Vol. 26, 1987, pp. 3069-3076.

[15] A. Louche, M. Maurel, G. Simonnot, G. Peri and M. Iqbal, "Determination of Ångström’s Turbidity Coefficient from Direct Total Solar Irradiance Measurements", Solar Energy, Vol. 38, 1987, pp. 89-96.

[16] T. Ingold, C. Mätzler, N. Kämpfer and A. Heimo, "Aerosol optical depth measurements by means of a Sun photometer network in Switzerland," Journal of Geophysical Research, Vol. 106, 2001, pp. 27537-27554.

[17] E. Gerasopoulos, M. O. Andreae, C. S. Zerefos, T. W. Andreae, D. Bali1, P. Formenti, P. Merlet, V. Amiridis, and C. Papastefan ou, "Climatological Aspects of Aerosol Optical Properties in Northern Greece", Atmospheric Chemistry and Physics, Vol. 3, 2003, pp. 2025-2041

[18] A. Smirnov, B. N. Holben, Y. J. Kaufman, O. Dubovik, T. F. Eck, I. Slutsker, C. Pietras, and R. N. Halthore, “Optical Properties of Atmospheric Aerosol in Maritime Environments," Journal of the Atmospheric Sciences, Vol. 59, 2002, pp. $501-523$.

[19] S. Rana, Y. Kant, and V.K. Dadhwal, "Diurnal and Seasonal Variation of Spectral Properties of Aerosols over Dehradun, India", Aerosol and Air Quality Research, Vol. 9, No.1, 2009, pp. 32-49. 